\title{
Social-Psychological Determinants Of Anxiety Disorder (SAD) Among Youth (With Reference To Karachi University)
}

\author{
Rana Saba Sultan \\ Ambreen Akber \\ \& \\ Erum Zarrar \\ Department of Sociology \\ University of Karachi
}

\begin{abstract}
The present study is "A study of Causes of Anxiety Disorder (SAD) among youth of Karachi University; deals with behavior patterns and expected to reflect on the type of society and its attitude towards SAD. The present research is an exploratory research. This study is based on the concept of level of sadness among youth of Karachi University. The mixed research approach quantitative and qualitative was adopted. The population of the study was Karachi University students; 120 students were selected through purposive sampling. Five hypotheses were formulated, from which three were accepted and two were rejected. Hence it is proved that there is a relationship between level of sadness with parents and gender, and this is also proved that there is a relationship between sadness and marital status and hence it is also proved that there is a relationship between level of troubled with appearance and gender, it is also found that there is a strong relationship between problem in decision making and cultural background and level of feeling of sadness and age. To test the hypotheses, statistical methods were applied to the data described in the contingency tables. The chi-square test was applied to test the existence of the relationship between two variables of hypothesis, and if the null hypothesis is rejected then the log linear models were also used to measure the degree of relationship. The hypotheses were then finally interpreted and the results were obtained.
\end{abstract}

\section{تلخيص المقالم}

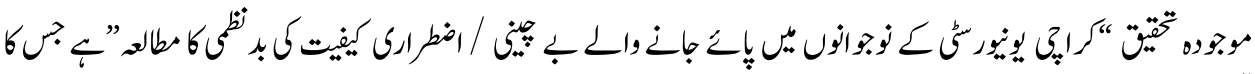

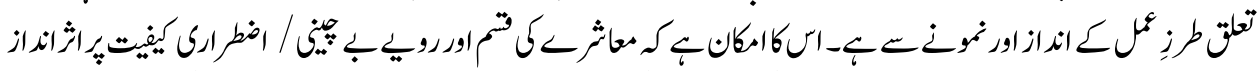

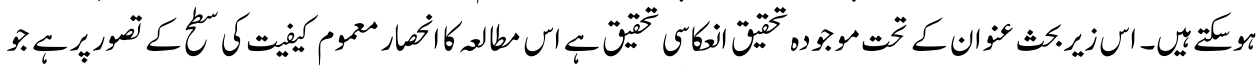

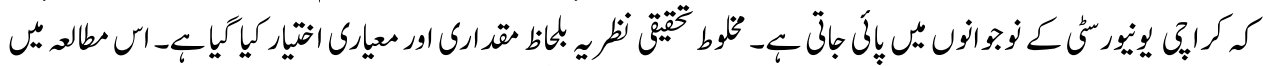

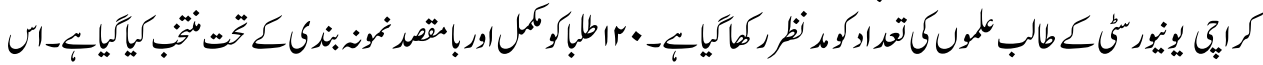

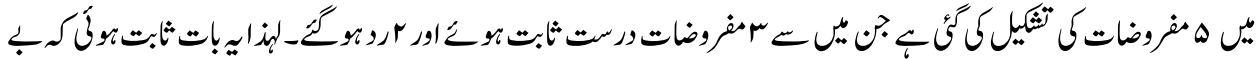

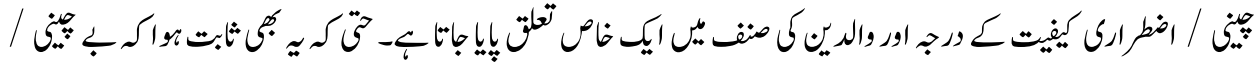

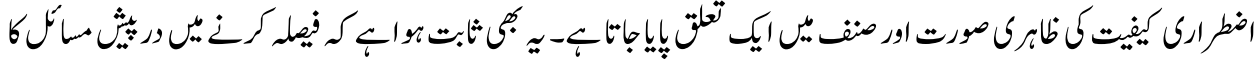

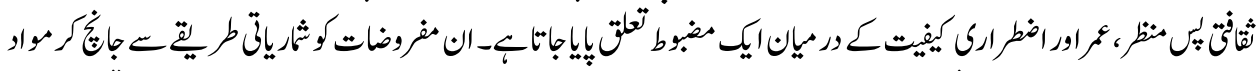

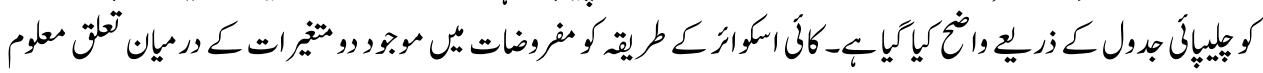

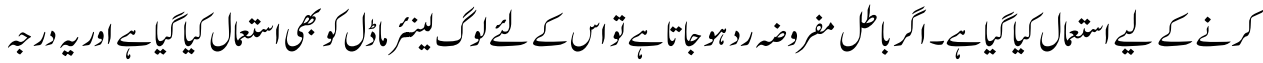

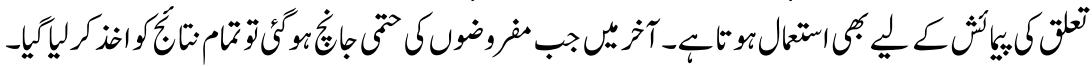




\section{Introduction}

Social anxiety disorder (SAD) now arises among young generation in present era. Sadness is a common disorder, with major depression among youth in academic functioning. Sadness is common in both gender and is now a difficulty regarding different aspects. The relationship between the developments of sadness within youth population is a promising area of inquiry. The increase in sadness, where symptoms are present but do not meet criteria for a depressive or social anxiety disorder, has been linked to developmental changes in youth. It is hard even for researchers to define SAD and the normal and abnormal behavior. There are multiple factors that contribute to such behaviors (Santrok, 2001; Ingram \& Price, 2000). Focus in the field of developmental psychopathology has been made upon the identifying, studying, and confirming the pathways of development in young children's disorders and problems. Relationship between the various risk factors of specific diseases is conceptualized in order to help them adapt and cope up with life and their adulthood.

Sadness is the Sadness is the most common reason for referring treatments and therapies to youngsters. Anxiety and depression are major debilitating and pervasive aspects of development in youth (Santrok, 2001). These i.e. anxiety and depression are conditions that greatly impair social, emotional and psychological well-being of a person. These are also called the common cold of mental disorder. These have adverse affects on interpersonal relationships and are economically and socially harmful to society (Dozois and Dobson, 2004; Barlow, 2002; Gotlib \& Hammen, 2002).

Given the fact that Sadness proves to be economically unfavorable to both individuals and society. Models must be made by researchers to help in understanding better, the development of the problems esp. the relationship between social designs of life in a normal population and sadness. This can help facilitate intervention strategies. Plato and Aristotle have researched on anxiety and depression" (Barlow \& Durand, 2011, p. 250).

\section{Social Anxiety Disorder (SAD)}

(Social Anxiety Disorder) is a condition of persistent, excessive, and unreasonable fear of facing strangers and their criticism against one, in a particular situation or performance. The individual fears that his/her anxiety will be easily detected and it will be embarrassing for him/her. Situations that are feared by the individual automatically arouse anxiety and fear when they occur or are about to occur. These are therefore either avoided or are endured with anxiety, stress and fear growing within. A person's normal routine, activities, career, social life and all are affected by it and one is in great distress about having such a phobia. The duration of SAD is 6 months in people above 18 years of age. This fear is not due to physiological effects of medicines, drugs etc. or a medical 
condition not accounted for by another medical disease. (DSM-1V, 2004) Depression is "A psychiatric disorder characterized by an inability to concentrate, insomnia, loss of appetite, feeling of extreme sadness, guilt, helplessness and hopelessness and thoughts of death". (APA, 2009)

"Depression is a chronic or recurrent mental disorder that impairs person to carry out his normal routine, perform tasks properly and fulfill responsibilities. In this a person faces loss of appetite, insomnia, depressed mood, self-worth is low, guilty feeling, loss of interest, low energy, low focus on work and loss of enjoyment and pleasure. At its worst it can lead to suicide. 850,000 people commit suicide ever year due to depression, according to WHO, 2001.

\section{Symptoms of Sadness \\ Physical}

Different people experience varying symptoms of sadness. Some of the symptoms are upset stomach, pain in the body, bowel problems like diarrhea, fatigue, headaches and being tearful all the time. Depression often manifests itself through physical symptoms. You may have disturbances you may experience nausea, loss of appetite, over-eating or eating very little, imbalance in health and routine, sleep disturbances etc.

\section{Emotional Symptoms}

Sadness often is a result of an occurrence e.g. death of a beloved or ending a relationship or being emotionally hurt by someone. Sometimes, sadness occurs without any reason or stimulus. Some of the emotional symptoms of sadness are anger, anxiety, low self-worth, irritability, fatigue, hopelessness and feeling that life has become meaningless.

\section{Social Avoidance}

When you're sad, you may feel like withdrawing from others. You might feel like spending more time on your own, and you may even avoid people whose company you typically enjoy. Other social symptoms of sadness include talking less or avoiding or ignoring other types of interactions such as phone calls or emails. However, some people react differently to feelings of sadness. They may actively seek out those who will listen to their feelings or complain about their situation.

\section{Cognitive Symptoms}

Sadness can interfere with your ability to process information and to think objectively. You may feel like you have a hard time concentrating or experience difficulty focusing 
on specific tasks. It can be difficult for you to make decisions or to remember certain things. (Dobson, 2011) The symptoms of sadness among youth are different. Usually youngsters recognize their fears of being publicly humiliated are unreasonable or excessive.

\section{Expressions of Anxiety in Young Includes}

Expressions of anxiety in young include excessive, unfavorable and persistent fear of facing strange people, being judged by them and being made a target of criticism. The fear of doing something humiliating in front of them, or failing to conceal one's anxiety and fear at such an occasion causes anxiety ad panic attacks at times too. The person tries to avoid such situations if possible or endure it silently. It adversely affects all aspects of a person's life like his/her routine, chores, health and relationship. Such people have a tendency to throw tantrums, cry often avoid socializing with new people, 'freezing' or 'becoming numb' at social events. They develop fear of speaking or performing in front of others. Its duration is approximately 6 months or more. People with SAD often tend to work in an un-ambitious manner, just sticking to their work and try to stay underachieved to avoid the attention of people, to avoid being promoted or compelled to participate in events or groups. They have few friends and have problems developing relationships, maintaining them and dating. In chronic severe cases many develop psychological disorders like depression or abuse of a substance.

\section{Causes of Sadness among Youth}

There are several factors which are contributors and cause of Sadness in Youth.

\section{Physical Appearance and Personality}

The youth today is dictated by the media. Most and are highly influenced by the picture media shows of style statements, personality, physical appearance and way of living. As a result they (more girls than boys) feel discontented with themselves, their attire, and their way youngsters follow of life. The focus becomes looking slim and smart which leads espcially girls to starve themselves, becoming anorexic and having eating disorders in order to lose weight and looking glamorous.

\section{Break Down in Group Relationship}

Personal loss or break up in a relationship is another cause of depression in youth. The young stars who experience such a thing as breaking up with girlfriend or boyfriend, death of parents or a beloved, losing good friends etc, find it very hard to handle themselves and compose themselves in such situations. They become extremely sensitive 
and vulnerable and can easily be provoked to behave unreasonably by making gags or jokes on them, or criticizing on them. They start isolating themselves from social events and parties. Failure or rejection terribly dishearten them and even random statements made by their close ones hurt them and trigger them easily. Their negative thinking also increases. At a young age, the human body is undergoing many anatomical, psychological and physiological changes in their body via a network of hormones, neurotransmitters and nervous system. Young people are unable to comprehend these developments which then also prove to be another cause of youth sadness.

\section{Physiological and Psychological Changes}

The human body, with its enormous network of neurotransmitters, introduces a lot of anatomical, physiological and psychological changes during young age. Sometimes, youth are not able to understand these changes well, and this becomes another of the cause of youth sadness.

Psychiatric disorder in family history also can be genetically transferred in the next generation and hence can surface during adult age or childhood. Genetically transferred until mental disorders is one cause of youth depression and requires professional help and therapies. Youngsters with family history of bipolar disorder can show symptoms of bipolar depression at an early age.

\section{The Gender Shift}

Equal number of boys and girls experience depression during the gender shift before adolescence. Around $10 \%-15 \%$ of total adolescents experience moderate to severe depression. However a dramatic change is seen at and after 13 years of age in which the ratio of girls to boys depressed is 2:1. This ratio is independent of ethnic or racial reasons and has been seen in (National Institute of Mental Health: 2009). It is fact that the causes of social anxiety are unreasonable, debilitating fear of being judged or publicly humiliated.

\section{Literature Review}

Psychodynamic theories emphasize mainly on the unresolved underlying issues that are expressed by a person through anxiety and depression symptoms. Sigmund Freud mentioned anxiety as a mechanism of defense for the unconscious, socially unacceptable and repressed impulses. (Davison, Neale, Blankstein, \& Flett, 2005). Numerous psychoanalysts believe that unconscious negative feelings are produced in depressed persons towards their beloved causing anger to turn inward. 
Freud stated that this is a defense mechanism to cope with socially unacceptable feelings. Unfortunately, there is little empirical evidence to support these psychodynamic assumptions (Barlow \& Durand, 2005; Davison, et al., 2005; Kandel, 1999). Probably in Africa around 50,000 years ago, modern human evolved. Human genome underwent many mutations which led to the development of modern human brain, that had the intelligence to make sophisticated tools and weapons aiding them in hunting and work, These changes further led to the development of complex social systems that gave the species enormous independence from environmental conditions. To support these social systems, humans evolved high-level motivations to compete for the approval and support of others (Barkow, 1989; Gilbert, 2001). Our species needs to be liked, valued, and approved of in order to elicit parental investment, develop supportive peer relationships, attract desirable mates, and engage successfully in many types of social relationships (Tooby \& Cosmides, 2013). Ostracism from the social group impacts negatively on a variety of healthrelated variables, including one's self-esteem and sense of belonging (Baumeister \& Leary, 1995; Baumeister \& Tice, 1990). As a result, humans naturally fear negative evaluation by their peers. The maladaptive expression of this evolutionarily adaptive concern is social anxiety disorder (sad). With the core feature of fears of negative evaluations from others, one can imagine the range of social interactions that can provoke social anxiety. These are events such as writing and eating in public, partying, meeting unfamiliar people, or dating, starting or maintaining conversation with leaders or figures of authority etc.

Among social fears, a particularly challenging event is public speaking, and indeed this is the most commonly feared social situation among individuals with sad (e.g., Pollard \& Henderson, 1988). There is proof that the rate of generalized subtype of SAD is increasing in United States of America espcially among middle-class, married, white people (Heinberg, Stein, Hiripi \& Kessler 2000). According to Heinberg et. al. 2000 , SAD has a lifetime prevalence among $5 \%$ to $15 \%$ youth of USA and has become quite common.

Aaron Beck (1967), views in his Cognitive Theory of Depression that irrational beliefs and elsewhere indicate the cognitive processes, play a decisive role in emotional behaviour. Freud was also a cognitive theorist for his viewed depression as resulting from a person's belief that loss is a withdrawal of affection. According to Beck $(1965,1985$, 1987), in childhood and youth, individuals develop a negative schema through depressive behavior of parents, losing parents, peer or social rejection, series of tragic events and criticism or humiliation from elder or a teacher.

The negative schemata, together with cognitive biases or distortions, maintain what beck called the negative triad negative views of the self the world, and the future. 


\section{Objectives of the Study}

- To find out the frequency of SADNESS among youth.

- To find out the demographic characteristics of SADNESS among youth.

- To find out the personality associated factors, to explore the appearance troubles.

- To find out the association of SADNESS with family related factors.

- To find out the social Anxiety and SAD in relation to depression.

- To find out the depression associative 'tragedy trauma' with SADNESS.

\section{Hypotheses}

- Level of relationship is likely to be related with gender.

- Level of SAD (social anxiety disorder) is likely to be related with marital status.

- Level of Associated factors Trouble with appearance is likely to be related with gender.

- Level of feelings of sadness is likely to be related with age.

- Level of problem in decision making is likely to be related with cultural background

\section{Research Methodology}

The present research is an exploratory. The mixed research approach quantitative and qualitative was adopted. The population of the study was Karachi University students; 120 students were selected through purposive sampling. The researcher has taken $33 . \%$ respondents from Education department, 33\% respondents From Psychology department and the rest of $33 \%$ respondents from Sociology Department of Karachi University. $15.8 \%$ respondents belonged to Class B.S-I, and 20\% respondents belonged in Class B.SII, other $27.5 \%$ respondents belonged to Class B.S-III and the rest of all 36.7 respondents belonged to Class B.S-IV. The data collection comprised of a structured questionnaire. Then data was coded, entered in computer and analyzed to draw the results for simple frequencies and contingency tables. The Chi-square method was applied to test the validity of hypotheses and verify the relationship between two variables. 


\section{Interpretation of Data Analyses}

\section{Table 1}

Contingency Tables Showing Relationship between Relationship with Parents and Gender

$\mathrm{H}_{\mathrm{O}}=$ There is no relationship between level of Relationship with Parents and gender. $\mathrm{H}_{\mathrm{A}}=$ Level of Relationship with Parents is likely to be related with gender.

\begin{tabular}{|l|c|c|c|c|}
\hline \multicolumn{1}{|c|}{ Gender } & \multicolumn{2}{c|}{ Relationship with Parents } & \multirow{2}{*}{ Total } \\
\hline Male & Complicated & Normal & Frank & \\
\hline Female & 7 & 28 & 13 & 48 \\
\hline Total & 6 & 29 & 37 & 72 \\
\hline
\end{tabular}

Chi-Square Obtained $\left(\mathrm{x}^{2}\right.$ овт $)=7$

Chi-Square Critical $\left(\mathrm{x}^{2}{ }_{\text {CRIT }}\right)=5.991$

Level of Significance $=0.05$

Degree of Freedom $=2$

Co-efficient of Correlation $=0.23$

\section{Results}

- The $\mathrm{x}^{2}$ obtain is larger than $\mathrm{x}^{2}$ critical value at df 2 at level of significance. Therefore, $\mathrm{H}_{\mathrm{A}}$ is accepted and $\mathrm{H}_{\mathrm{O}}$ is rejected.

- There is a strong relationship between level of Relationship with Parents and Gender.

\section{Table 2}

\section{Contingency Tables Showing Relationship between Sadness (Social Anxiety Disorder) and Marital Status}

$\mathrm{H}_{\mathrm{O}}=$ There is no relationship between level of Sadness (Social Anxiety Disorder) and Marital Status.

$\mathrm{H}_{\mathrm{A}}=$ Level of Sadness (Social Anxiety Disorder) is likely to be related with Marital Status.

\begin{tabular}{|l|c|c|c|c|}
\hline Marital status & \multicolumn{3}{|c|}{$\begin{array}{c}\text { Level of Sadness } \\
\text { (Social Anxiety Disorder) }\end{array}$} & \\
\cline { 1 - 2 } & No & Sometimes & All the time & \\
\hline Married & 15 & 11 & 7 & 33 \\
\hline Single & 27 & 9 & 7 & 43 \\
\hline Divorce & 12 & 24 & 8 & 44 \\
\hline Total & $\mathbf{5 4}$ & $\mathbf{4 4}$ & $\mathbf{2 2}$ & $\mathbf{1 2 0}$ \\
\hline
\end{tabular}


Chi-Square Obtained $\left(\mathrm{x}^{2}\right.$ ОВТ $)=13.121$

Chi-Square Critical $\left(\mathrm{x}^{2}\right.$ CRIT $)=9.488$

Level of Significance $=0.05$

Degree of Freedom $=4$

Co-efficient of Correlation $=0.313$

\section{Results}

- The $\mathrm{x}^{2}$ obtain is larger than $\mathrm{x}^{2}$ critical value at df, 4 at level of significance. Therefore, $\mathrm{H}_{\mathrm{A}}$ is accepted and $\mathrm{H}_{\mathrm{O}}$ is rejected.

- There is a strong relationship between level of Sadness and Marital Status.

Table 3

Contingency Tables Showing Relationship between Associated Factors Trouble with Appearance and gender

$\mathrm{H}_{\mathrm{O}}=$ There is no relationship between level of Associated Factors Trouble with Appearance and gender.

$\mathrm{H}_{\mathrm{A}}=$ Level of level of Associated Factors Trouble with Appearance is likely to be related with gender.

\begin{tabular}{|l|c|c|c|c|}
\hline \multicolumn{1}{|c|}{ Gender } & \multicolumn{3}{|c|}{$\begin{array}{c}\text { Associated Factors } \\
\text { Trouble with Appearance }\end{array}$} & \multirow{2}{*}{ Total } \\
\hline & No & Average & Yes & \\
\hline Male & 27 & 13 & 8 & 48 \\
\hline Female & 39 & 17 & 16 & 72 \\
\hline Total & $\mathbf{6 6}$ & $\mathbf{3 0}$ & $\mathbf{2 4}$ & $\mathbf{1 2 0}$ \\
\hline
\end{tabular}

Chi-Square Obtained $\left(\mathrm{x}^{2}\right.$ овт $)=0.579$

Chi-Square Critical $\left(\mathrm{x}^{2}{ }_{\text {CRIT }}\right)=5.991$

Level of Significance $=0.05$

\section{Results}

- The $\mathrm{x}^{2}$ obtain is lesser than $\mathrm{x}^{2}$ critical value at $\mathrm{df}, 2$ at level of significance. Therefore, $\mathrm{H}_{\mathrm{A}}$ is rejected and $\mathrm{H}_{\mathrm{O}}$ is accepted.

- There is a strong relationship between level of associated Factors Trouble with Appearance and Gender. 


\section{Table 4}

\section{Contingency Tables Showing Relationship between Feeling of Sadness and Age}

$\mathrm{H}_{\mathrm{O}}=$ There is relationship between level of Feeling of Sadness with Age.

$\mathrm{H}_{\mathrm{A}}=$ Level of Relationship with Feeling of Sadness in is likely to be related with age.

\begin{tabular}{|l|c|c|c|}
\hline \multirow{2}{*}{ Age } & \multicolumn{2}{|c|}{ Feeling of Sadness } & \multirow{2}{*}{ Total } \\
\cline { 2 - 3 } & Sadness Present & Sadness Absent & \\
\hline $15-20$ & 11 & 18 & 29 \\
\hline $21-25$ & 29 & 32 & 61 \\
\hline $26-30$ & 6 & 12 & 18 \\
\hline $31-35$ & 7 & 5 & 12 \\
\hline Total & $\mathbf{5 5}$ & $\mathbf{6 5}$ & $\mathbf{1 2 0}$ \\
\hline
\end{tabular}

Chi-Square Obtained $\left(\mathrm{x}^{2} \mathrm{OBT}\right)=2.62$

Chi-Square Critical $\left(\mathrm{x}_{\text {CRIT }}{ }^{2}\right)=7.815$

Level of Significance $=0.05$

Degree of Freedom $=3$

\section{Results}

- The $\mathrm{x}^{2}$ obtain is lesser than $\mathrm{x}^{2}$ critical value at $\mathrm{df}, 3$ at level of significance. Therefore, $\mathrm{H}_{\mathrm{A}}$ is rejected and $\mathrm{H}_{\mathrm{O}}$ is accepted.

- There is a strong relationship between level of Relationship with Parents and Gender.

Table 5

\section{Contingency Tables Showing Relationship between Problem in Decision Making and Cultural Background}

$\mathrm{H}_{\mathrm{O}}=$ There is relationship between level of Problem in Decision Making and Cultural Background.

$\mathrm{H}_{\mathrm{A}}=$ Level of Problem in Decision Making is likely not to be related with Cultural Background.

\begin{tabular}{|l|c|c|c|c|}
\hline $\begin{array}{c}\text { Cultural } \\
\text { Background }\end{array}$ & \multicolumn{3}{|c|}{ Problem in Decision Making } & \multirow{2}{*}{ Total } \\
\cline { 1 - 4 } & No & A bit & Yes & \\
\hline Rural & 11 & 31 & 7 & 49 \\
\hline Urban & 23 & 42 & 6 & 71 \\
\hline Total & $\mathbf{3 4}$ & $\mathbf{7 3}$ & $\mathbf{1 3}$ & $\mathbf{1 2 0}$ \\
\hline
\end{tabular}

Chi-Square Obtained $\left(\mathrm{x}^{2}{ }_{\text {ОВТ }}\right)=1.912$

Chi-Square Critical $\left(\mathrm{x}_{\text {CRIT }}{ }^{2}=5.991\right.$

Level of Significance $=0.05$

Degree of Freedom $=2$ 


\section{Results}

- The $\mathrm{x}^{2}$ obtain is lesser than $\mathrm{x}^{2}$ critical value at $\mathrm{df}, 2$ at level of significance. Therefore, $\mathrm{H}_{\mathrm{A}}$ is rejected and $\mathrm{H}_{\mathrm{O}}$ is accepted.

- There is a strong relationship between level of problem in Decision Making and Cultural Background.

\section{Findings of Simple Table}

- $24.2 \%$ respondents were from $15-20$ years age group, $50.8 \%$ respondents are 21 25 , and $60 \%$ respondents were female.

- $40.8 \%$ respondents belonged from rural area while $59.2 \%$ respondents belonged from urban area. $100 \%$ respondents have same religious background.

- $6.7 \%$ respondents were married, other $87.5 \%$ respondents were Single and the other $5.8 \%$ respondents were Divorce.

- $28.3 \%$ respondents belonged to Nuclear Family, 64.2\% respondents belonged to Joint Family and other 7.5\% respondents belonged to Extended Family.

- $10.8 \%$ respondents Family Income is around 20,000-30,000, other $12.5 \%$ respondents Family Income is around 30,001-40,000, 55\% respondents Family Income is around 40,001-50,000 and 21.7\% respondents Family Income is around 50,001 and above.

- $10.8 \%$ respondents impressed by other's Appearance, 5.8\% respondents impressed by other's Body Language, $17.5 \%$ respondents impressed by other's Behaviour, $14.2 \%$ respondents impressed by other's looks, 35.0\% respondents impress by other's Nature and $16.7 \%$ respondents impress by other's Way of Talking.

- $10.8 \%$ respondent's Relationship with their Parents was Complicated and stress, 47.5\%respondent's Relationship with Parents was Normal and Other 41.7\% respondent's Relationship with Parents were Frank and Stress-less.

- $15.8 \%$ respondent's Parent's not listen their Problems, 27.5\% respondent's Parent's sometime listen their Problems and 56.7\% respondent's Parent's listen their Problems.

- $9.2 \%$ respondents Parent's not support them finically and morally, $43.3 \%$ respondents Parent's sometime support them finically and morally while $47.5 \%$ respondents Parent's support them finically and morally.

- $12.5 \%$ respondents Relationship with Siblings were complicated and Harsh, $49.2 \%$ respondents Relationship were Normal and 38.3\% respondents Relationship with Siblings were Comfortable together.

- $20 \%$ respondents did not spend their time at home, $20 \%$ respondents little bit spend their time at home and $60 \%$ respondents mostly spend their time at home. 
- $51.7 \%$ respondents Much Closer with their parents/Husband and 48.3\% respondents Much Closer with siblings/friends.

- $28.3 \%$ respondents do not have Problem in Decision Making, $60.8 \%$ respondents have a bit Problem in Decision Making and 10.8\% respondents have Problem in Decision Making.

- $7.5 \%$ respondents did not want More Achievement in short time, 60\% respondents often want More Achievement in short time and 32.5\% respondents want all the time More Achievement in short time.

- $50.8 \%$ respondents were not Hopeless about Future, 38.3\% respondents sometime Hopeless about Future and 10.8\% respondents were Hopeless about Future all the time.

- $32.5 \%$ respondents were not Aggressive with People, 56.7\% respondents were sometime Aggressive with People and 10.8\% respondents were Aggressive with People.

- $40.8 \%$ respondents were not thinking to humiliate themselves, $27.5 \%$ respondents were often thinking to humiliate themselves and $31.7 \%$ respondents were thinking all the time to humiliate themselves.

- Majority 38.3\% respondents were often Feeling like Crying and 35\% respondents were Feeling all the time like Crying. Majority of $47.5 \%$ respondents are sometime Get Tired for any reason., Mostly 35\% \%respondents were sometime depressed in mood (sadness, hopeless, worthless) and 33.3\% \% respondents were expressed depression in mood (sadness, hopeless, worthless). $54.2 \%$ respondents were not having feeling of sadness while $45.8 \%$ respondents were having feeling of sadness.

- $44.2 \%$ respondents did not have feeling of self dislike, $37.5 \%$ respondents have sometime feeling of self dislike while $18.3 \%$ respondents have feeling of self dislike.

- $34.2 \%$ respondents are not Aggressive or Rude, $56.7 \%$ respondents are sometimes Aggressive or Rude and 9.2\% respondents are Aggressive or Rude.

- $51.7 \%$ respondents had no Trauma in their lives, $37.5 \%$ respondents had Trauma in their lives, and $10.8 \%$ respondents had Trauma; it smashed their lives.

- $9.2 \%$ respondents victimize by close cone's death, $17.5 \%$ respondents victimize by close cone's accidental death, $21.7 \%$ respondents victimize by close cone's cheated with them and the rest of all $51.7 \%$ respondents are not victimize by any type of Trauma.

- $11.7 \%$ respondents had affects of trauma in their lives by Failure in Love, $17.5 \%$ respondents had affects of trauma in their lives by serious medical illness, 19.2\% respondents had affects of trauma in their lives by hopeless all the time and the rest of all $51.7 \%$ respondents had no affects of trauma in their lives. 
- $37.5 \%$ respondents do not scare being criticized, $38.3 \%$ respondents' sometime scare being criticized and $24.2 \%$ respondents scare being criticized.

- $40.8 \%$ respondents do not afraid of doing things, when people watching them, $40 \%$ respondents sometime afraid of doing things, when people watching them and $19.2 \%$ respondents much Afraid of doing things, when people watching them.

- $40.8 \%$ respondents are not counter it; sweating butterflies in stomach, $44.2 \%$ respondents are somehow counter any of it; sweating butterflies in stomach and $15 \%$ respondents are counter; sweating butterflies in stomach.

- $45 \%$ respondents do not scare to talking to strangers, $36.7 \%$ respondent's sometime scare in talking to strangers while $18.3 \% \%$ respondents always scare in talking to strangers.

- $55 \%$ respondents have not Trouble with Appearance, 25\% respondents have sometimes Trouble with Appearance and 20\% respondents have severe Trouble with Appearance.

\section{Conclusions}

The topic of the present study is "A study of Causes of Sadness among youth of Karachi University". This topic is one of the concerns of the subject matter of Sociology as it deals with behavior patterns. The study is expected to reflect on the type of society and its attitude towards SAD.

The researcher has made a humble attempt to empirically assess the causes of SAD among youth of Karachi University, Pakistan. Sadness exists in all age group of youngsters. Many students openly admit that they are victim of sadness, while others are not as bold as to admit it openly for fear of being called boring and "dukhi Attma". 1

\section{Limitations of the Study}

The present research was limited to only a small sample due to shortage of time and resources. The universe of the study was too large; therefore it was not possible to cover all the aspects with the span of time and resources available to the researcher. Secondly, this research required private and personal affairs of people which most do not like to talk or be questioned about their social patterns about which they are very much emotional and conscious. In spite of these hurdles and limitations, the researcher did her best to gather are sound and reliable data as possible and established the best rapport with the respondents. 


\section{Recommendations}

- The present study is a comprehensive and elaborate research, conducted for the understanding of different social behaviors and their impact on overall personality development in the society.

- Several recommendations can be made to direct future investigations of the relationship to find the causes of social anxiety disorders; there was seen frustration, depression, and hopelessness in Karachi University students. Various measures should be taken to improve the research by installing credible and new apparatus and instruments.

- The present research deals with few selected variables other investigators should be conducted on large scale to probe into the factor and forces responsible for flourishing sadness in a society.

- Further research and is required to study in detail, the psychometric properties in calculating highly co morbid constructs, causes of demoralization leading to sadness, depression, and anxiety. Moreover, interventions on sub-clinical anxiety should be developed and tested upon. Future research may also be needed to further show relations between different variables and their strengths.

- The study was unable to fully explore all aspects and factors leading to sadness as summed scores were used to give a general relationship rather than item scores. Study can be made more vast and interesting by examining it in various other samples e.g. clinical samples, by testing the research on both the children and adult populations, by examining casual relationships among latent and measured variables and by using modern techniques, instruments and methods.

- Finally, structural research of longitudinal data would be valuable in the verification of sadness as a common etiological factor exerting strong impact on the pathogenesis, treatment and course of mood disorders.

\section{End Notes}

1. Dukhi Attma: one who remains in isolation and does not socialize.

\section{References}

Aaron, T. Beck (2005). Anxiety Disorder And Phobia, A Cognitive Perspectives Basic Book. New York: Hoeber.

American Psychiatric Association (2009). Diagnostic And Statistic Manual Of Mental Disorders, Edition IV, Washington DC, American Psychiatric Association.

Babbie, E. R. (1992). The Practice Of Social Research, Belmont, Calif: Wadsworth Pub. Co. 
Baker, L. Therese (1994). Doing Social Research, New York, Singapore, McGraw-Hill Company.

Barlow, D. H. \& Durand, M. (2011). Abnormal Psychology, (6 ${ }^{\text {th }}$ ed) Pensumliste Profession Psy.

Barkow (1989) Gilber (2001). Unsupervised Learning, Neural Computation, Journal Of Experimental Child Psychology.

Barlow, D. H. \& Durand, M. (2005). Anxiety And Its Disorders: The Nature And Treatment Of Anxiety And Panic. New York Guilford Press.

Baumeister, R.F. Tice (1990). Self Presentational Motivation Of Differences In SelfEsteem, Journal of Personality Psychological Bulletin.

Baumeister, R.F \& Leary, M.R. (1995). The Need To Belong, Journal of Personality Psychological Bulletin.

Buss, A. H. (1980). Self Consciousness And Social Anxiety. San Francisco, CA: Freeman.

Cosmides, L. Tooby, J. (2013). Evolution Psychology, New Perspectives On Cognitive And Motivation Annual Review Of Psychology 64, 201, 229.

Davison, Neal, Blankstein \& Flett (2005). Abnormal Psychology, University of New York at Stany Book, Ltd.

Dobson, SK. (2011). Cognitive Therapy, Washington, D.C: American Psychological Association Press.

Dozois, D.J.A. \& Dobson, S.K. (2004). Prevention of Anxiety And Depression, Washington, D.C; American Psychological Association Books.

In Deutsch, A., \& Fishman, H. (1963). The Encyclopedia Of Mental Health: Vol. I. New York, NY: Franklin Watts.

Freud Sigmund (1999). Analysis Of A Phobia In A Five-Year-Old Boy. Vol 10 London: Hogarth Press.

Gilbert (2001). Adult Cortical Dynamics, Psychological Reviews, pp, 78-467, 485. 
Gotlib, I.H. \& Hammer, CL. (2002). Handbook Of Depression, New York, Guilford Press.

Heimberg, R. G., Stein, Hiripi \& Kessler (2000). A Cognitive-Behavioral Model Of Anxiety In Social Phobia. Behaviour Research and Therapy, 35, pp, 741-756.

Khyati, Mehtalia \& G.K. Vankar (2004). Social Anxiety In Adolescents, Indian Journal of Psychiatry, 46(3) pp, 221-227

Pollard, C.A \& Henderson, J.G. (1988). Four Types Of Social Phobia In A Community Sample, Journal of Nervous and Mental Disease, pp, 440-445.

Sarantakos, S. (1998). Social Research, Melbourne: Macmillan.

Santrok, J.W. (2001). Adolescence: Mc Graw Hill, New York.

A Dictionary of Sociology (2005). Oxford University Press, UK.

WHO, The World Health Report (2001). Mental Health; New Understanding, New Hope.

Dr. Rana Saba Sultan is Professor in the Department of Sociology, University of Karachi.

Ms. Ambreen Akber is Ph.D. Research Scholar.

Ms. Erum Zarrar is Researcher. 